\title{
2D Images of Astrocytes in the Human Principal Olivary Nucleus: Monofractal Analysis of the Morphology
}

\author{
Damjan Stojić1, Dragana Radošević ${ }^{2}$, Nemanja Rajković1, Nebojša T. Milošević ${ }^{*}$ \\ ${ }^{1}$ Laboratory of Image Analysis, Institute of Biophysics, School of Medicine, University of Belgrade, Belgrade, Serbia \\ ${ }^{2}$ Laboratory of Neuroanatomy, Department of Anatomy, School of Medicine, University of Novi Sad, Novi Sad, Serbia \\ Email: *nebojsa.milosevic@med.bg.ac.rs
}

How to cite this paper: Stojić, D., Radošević, D., Rajković, N. and Milošević, N.T. (2021) 2D Images of Astrocytes in the Human Principal Olivary Nucleus: Monofractal Analysis of the Morphology. Journal of Biosciences and Medicines, 9, 38-48. https://doi.org/10.4236/jbm.2021.99004

Received: July 26, 2021

Accepted: September 4, 2021

Published: September 7, 2021

Copyright () 2021 by author(s) and Scientific Research Publishing Inc. This work is licensed under the Creative Commons Attribution International License (CC BY 4.0).

http://creativecommons.org/licenses/by/4.0/ (c) (i) Open Access

\begin{abstract}
Introduction: Current knowledge postulated glia as active participants in various metabolic processes within nervous tissue. The most numerous glial cells were astrocytes, and qualitative analysis divided them into two types based on their anatomical locations: fibrous and protoplasmic. The main goal of this research was to examine the morphological difference between types, analyzing four features of the image. The secondary objective of this research was to explore their morphology through maturation and aging. Materials and Methods: The material originated from bilateral sections of the human principal olivary nucleus, without disorders in the central nervous system. The brains were taken from 30 human cadavers (35 - 90 years) and cut into samples corresponding to dimensions of the principal olivary nucleus. A light microscope digitized the histological preparations. The selection of $294 \mathrm{im}-$ ages was analyzed by monofractal parameters derived from the box-counting. These parameters quantified four image properties (size, shape, complexity and homogeneity) of the glial body or whole glial cell. Results: The first results showed that images of two types of astrocytes were significantly different $(p<0.05$ and higher) in all properties of whole cells. The second results examined the differences between three age groups in both types of astrocytes. The differences between groups were more evident for protoplasmic than fibrous (nine vs. three parameters). Conclusions: The main limitation of this study lies in the fact that the quantification was performed only by fractal analysis techniques. Nevertheless, a detailed monofractal analysis of astrocytes was performed for the first time. Thus, although this study can be seen as an improvement of the previous qualitative results, future research will provide the complete procedure of the image analysis.
\end{abstract}




\section{Keywords}

Aging, Astrocytes, Box-Counting, Monofractal Analysis, Human Olivary Nucleus

\section{Introduction}

The description and first investigation of glial cells were started in the XIX century [1], and a few decades later, scientists thought that glial was the "glue" for nerve cells providing only passive assistance [2]. Instead, scientists discovered that the glia was an active participant in numerous metabolic processes within the nervous tissue [3]. Similar to nerve cells, the interaction of glial cells is an essential process for the transmission of pulses within the Central Nervous System (CNS). Several types of glial cells have been documented [4] [5]. Still, two types of astrocytes and oligodendrocytes were registered in our sample [6], i.e., the number of which was sufficient for further quantitative analysis (Figure 1).

The astrocytes are the most numerous glial cells, about $40 \%$ of the CNS cell population [7]. Qualitative investigations postulated a small star-shaped body with many extensions of different lengths, thicknesses and branches [6]. They are usually divided into two types based on their anatomical locations: fibrous and protoplasmic. Although the morphological difference between the types was visible (Figure 1), their histological structure was indistinguishable [7].

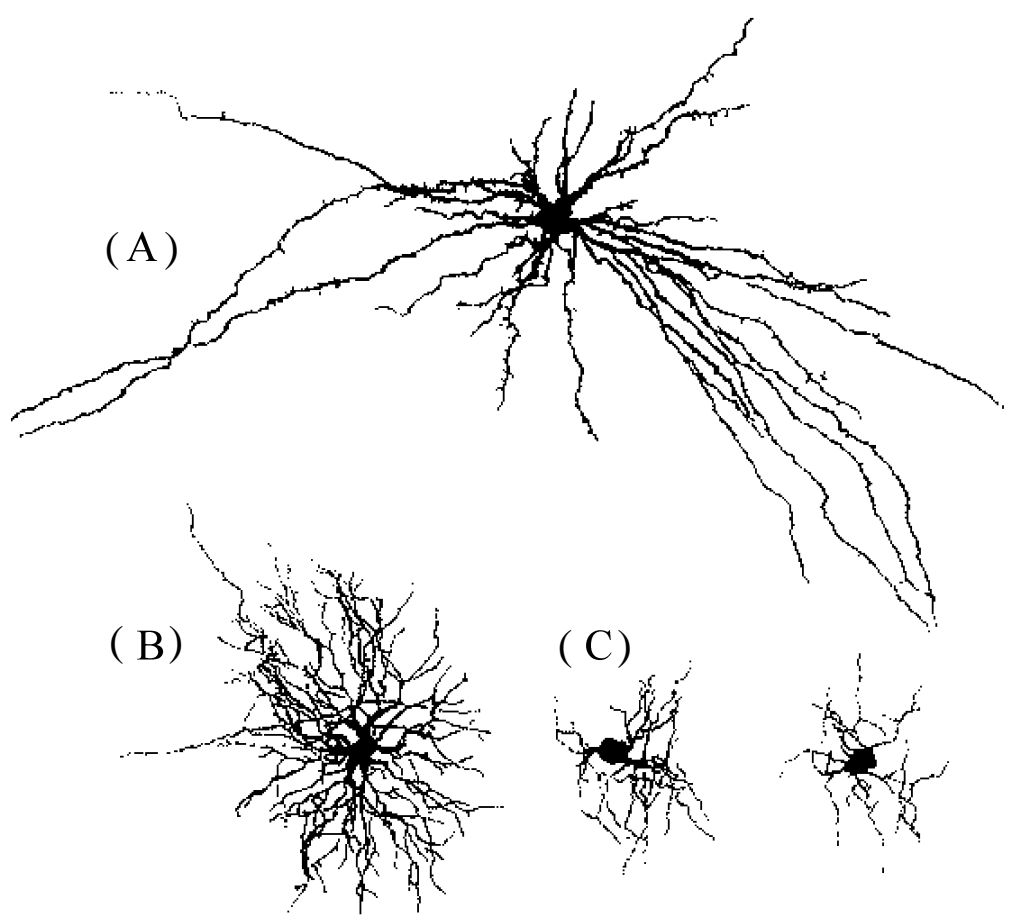

Figure 1. (A-C) Three types of glial cells in the CNS are drawn as they would appear with a Golgi stain: two types of astrocytes (A and B) are more prominent than oligodendrocytes (original image can be found in Neurohistology atlas at http://vanat.cvm.umn.edu/). 
At the same time, the aging process is characterized by time-dependent changes that lead to irreversible processes in organic systems [8]. The cascade of events has different dynamics, primarily determined by biological factors and divided into the primary and secondary cycles [9], i.e., the maturation and the aging. Changes at the cellular level [9] [10] include cell membrane damage, apoptosis, and cell division reduction. Although many astrocytes and their density have been studied with aging [11] [12], few studies have dealt with the morphological changes during aging [12].

The available literature lacks data on the morphology of glial cells [6], especially during aging [13]. So far, studies have mainly investigated changes in the number of cells during neurodegenerative diseases, but the total number of astrocytes remains the same [13] [14]. The latest qualitative analysis of the human Principal Olivary Nucleus (PON) [15] investigated the body and glial field, the number of primary extensions, the direction of their wings and branching. However, this study did not establish differences in examined glial types either confirmed morphological differences during aging in previous investigations [16]. Therefore, the main goal of this research was to investigate the morphology of two types of astrocytes using fractal techniques. Precisely, this research used the box-counting technique to quantify four features of the image: size, shape, complexity and homogeneity. Another objective was to investigate the morphology of astrocytes through maturation and aging.

\section{Material and Methods}

\subsection{The Patient Sample and Histological Procedure}

The samples of this study originated from bilateral sections of the PON of 30 humans. The brain samples belonged to histological collection from the department of Anatomy of the University of Novi Sad, and the Ethics committee approved the further investigation (01-3367/1). The samples were cut into $2 \mathrm{~cm} \times$ $1.25 \mathrm{~cm}$, which corresponded to dimensions of the human PON and treated with a modified Golgi method of silver impregnation by Kopsch-Bubenaite [17]. The previous publication [18] explained this procedure in detail. The tissue samples were cut on a sliding microtome, in a horizontal plane relative to the anatomical position of the PON, with a thickness of $70 \mu \mathrm{m}$.

\subsection{The 2D Image: Extraction and Editing}

The incisions of the PON were analyzed by optical microscope "Leica DC 100" (Leica Microsystems, Wetzlar, Germany) using the system magnification of 400x [19]. Adequate impregnated glial cells were evident in a series of optical sections (horizontal cross-sectional images), while any problematic cells were excluded from the sample [7]. All identified glial cells were permanently recorded and transformed into digital images using a digital camera "Leica DC 100" with accompanying software program "Digital Camera System" (Leica Microsystems, Heerbrugg, Switzerland). Any glial cell was recovered by analysis of several im- 
ages ranging from 3 to 12 in each set [19] [20]. Finally, each cross-sectional image was taken as color images (RGB) and saved in TIFF format (Figure 2(A)).

The digitized images, i.e., horizontal sections, were loaded into Image J

(http://rsbweb.nih.gov/ij, National Institute of Health, Bethesda, MD). Then, an anatomist (20+ years of experience) made further editing using various subcommands of the package. Firstly, the image of the entire neuron was reconstructed by subcommand " $Z$ Project", where all optical sections for a given cell merged into a single image. Then, the RGB image was converted into grayscale [19], and each image was converted into a binary format (Figure 2(B)) using the subcommand "Threshold" by adjusting the contrast. Meanwhile, the specialists reconstructed the trajectory of the soma and each extension [20] and removed all remains of artifacts (subcommand: "File: Delete"). Also, from each cell, anatomists digitally separated the body and attachments. Thus, the investigated sample consisted of 294 (precisely 588) binary images of the PON astrocytes.

\subsection{Monofractals Parameters}

The morphology was quantified using seven parameters that describe four image features (size, shape, complexity, and homogeneity). These parameters have been

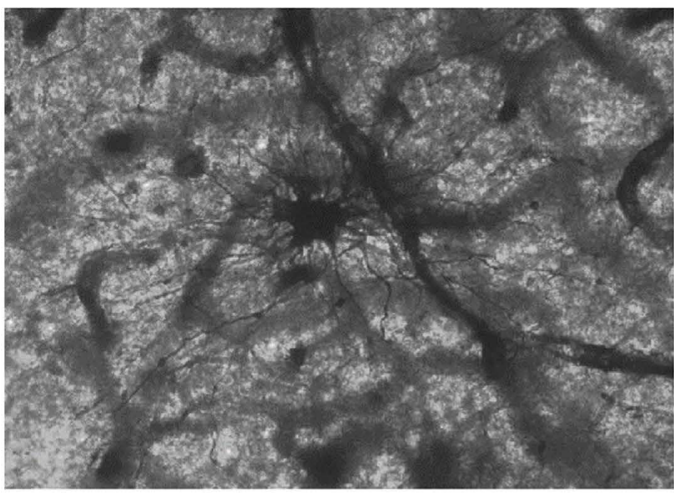

(A)

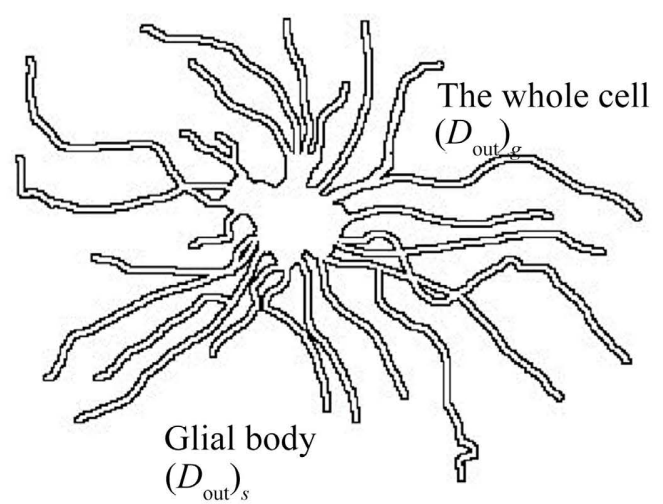

(C)

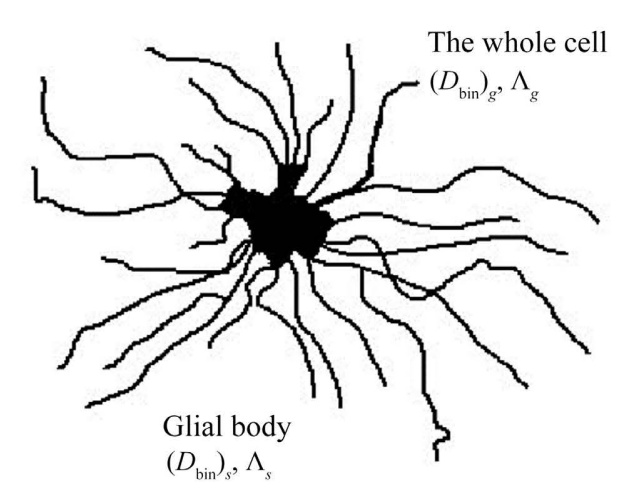

(B)

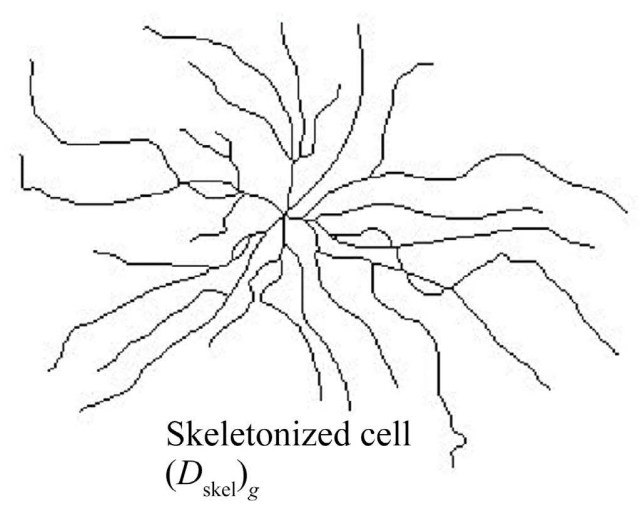

(D)

Figure 2. The digital image of the fibrous astrocyte from the human PON: grayscale image (A) and its conversion in binary format (B). The outline (C) and skeleton (D) images are derived from the binary image. The figure also illustrates monofractal parameters calculated on the adequate image. 
calculated using the box-counting method [21] [22] [23] [24], either by subcommand of Image J ("Fractal Box count") or by the FracLac plugin [25].

The monofractal parameters estimated the $2 \mathrm{D}$ projection of the glial soma and the glia. Concretely, 1$)$ the surface area with $\left(\left(D_{\text {bin }}\right)_{s}\right)$ and $\left.\left(\left(D_{\text {bin }}\right)_{g}\right), 2\right)$ the shape with $\left(\left(D_{\text {out }}\right)_{s}\right)$ and $\left.\left(\left(D_{\text {out }}\right)_{g}\right), 3\right)$ the complexity with $\left(\left(D_{\text {skel }}\right)_{g}\right.$ and 4$)$ the homogeneity with $\left(L_{s}\right)$ and $\left(L_{g}\right)$. The $\left(D_{\text {bin }}\right)_{s} L_{s}\left(D_{\text {bin }}\right)_{g}$ and $L_{g}$ were calculated either from a binary image of glial soma or the glia (Figure 2(B)) [26].

Also, the $\left(D_{\text {out }}\right)_{s}$ and $\left(D_{\text {out }}\right)_{g}$ were calculated from the outline image of glial soma or the glia (Figure 2(C)) with a one-pixel broad outline was generated in Image J: "Process-Binary-Outline" [27]. Finally, the $\left.\left(D_{\text {skel }}\right)_{g}\right)$ estimated on the glia's skeleton image (Figure 2(D)) when all extensions were reduced to a single-pixelwide line in Image J: "Process-Binary-Skeletonize" [27].

\subsection{Statistical Analysis}

The study has investigated the difference between cell types with a two-tailed $t$-test for independent samples. In contrast, statistical significance between groups was examined by one-way ANOVA with a Bonferroni post hoc test [28]. A value of $p<0.05$ was considered statistically significant. These statistical procedures were performed by the SPSS software package v23 (IBM SPSS Statistics, Chicago, IL, USA, demo version).

\section{Results}

\subsection{Morphological Analysis of Types}

The sample size indicated that the laws of nonparametric statistics should perform a presentation and further analysis. Thus, Table 1 showed the mean values (and standard errors) of seven monofractal parameters for two types of astrocytes and the corresponding $p$-value, obtained by the Bonferroni post hoc test.

The first investigation of Table 1 showed that protoplasmic type had higher means of shape and size than fibrous. However, only two parameters showed a significant difference: $p<0.001$ for the size $\left(\left(D_{\text {bin }}\right)_{g}\right)$ and $p<0.05$ for the shape

Table 1. The mean values \pm standard errors of seven monofractal parameters in two types are summarized as four properties. The significant differences were if the $p$-value was lower than 0.05 and marked with bold letters.

\begin{tabular}{ccccc}
\hline Property & Parameters & Fibrous & Protoplasmic & $p$ \\
\hline \multirow{2}{*}{ Size } & $\left(D_{\text {bin }}\right)_{s}$ & $1.728 \pm 0.006$ & $1.741 \pm 0.006$ & 0.089 \\
& $\left(D_{\text {bin }}\right)_{g}$ & $1.410 \pm 0.004$ & $1.436 \pm 0.003$ & $<0.001$ \\
Shape & $\left(D_{\text {out }}\right)_{s}$ & $1.118 \pm 0.003$ & $1.121 \pm 0.003$ & 0.449 \\
& $\left(D_{\text {out }}\right)_{g}$ & $1.290 \pm 0.003$ & $1.299 \pm 0.003$ & 0.024 \\
Complexity & $\left(D_{\text {skel }}\right)_{g}$ & $1.170 \pm 0.003$ & $1.151 \pm 0.004$ & $<0.001$ \\
\multirow{2}{*}{ Homogeneity } & $\Lambda_{s}$ & $0.114 \pm 0.003$ & $0.114 \pm 0.002$ & 0.889 \\
& $\Lambda_{g}$ & $0.624 \pm 0.008$ & $0.586 \pm 0.005$ & $<0.001$ \\
\hline
\end{tabular}


$\left(\left(D_{\text {out }}\right)_{g}\right)$. The parameters of the complexity and homogeneity showed the opposite conclusion. Furthermore, in this case, two parameters were statistically different $(p<0.001)$ : one for the complexity $\left(\left(D_{\text {skel }}\right)_{g}\right)$ and one for the homogeneity $\left(L_{g}\right)$. Finally, the main result of this analysis was that the monofractal parameters performed on the image of the whole-cell more accurately distinguish the morphology of astrocytes than on the body (Table 1). Also, the two astrocyte types were statistically different in all four morphological properties (size, shape, complexity and homogeneity). Figure 3 showed these types, from the sample analyzed, with values of monofractal parameters close to the mean values from $\mathrm{Ta}$ ble 1 .

\subsection{Morphological Analysis with Age}

The investigated pool of images belonged to samples of the human PON aged from 35 to 90 years. In age distribution, three age groups were recognized: group A (the second group of maturation), group $\mathrm{B}$ (the first group of aging) and group C (the second group of aging). The first group consisted of 104 images (35 - 60 years), the second of 84 images (61 - 75 years) and the third of 100 images (76 - 90 years). Again, all groups had more than 50 images, and morphological differences were investigated by one-way ANOVA followed by Bonferroni post hoc test. Therefore, the statistical evaluation results between the age groups in both types of astrocytes were presented in Table 2.

The table clearly showed that the most significant differences existed for the protoplasmic than for the fibrous type (11 vs. 5). In fibrous type, only three characteristics differed: the $\left(D_{\text {bin }}\right)_{s}$ in two pairs A-C and B-C, the $\left(D_{\text {out }}\right)_{g}$ in A-B and the $L_{g}$ in two pairs A-B and A-C. Conversely, in the protoplasmic type, six parameters showed significant differences: four properties of the glia $\left(\left(D_{\text {bin }}\right)_{g},\left(D_{\text {out }}\right)_{g}\right.$, $\left(D_{\text {skel }}\right)_{g}$ and $\left.L_{g}\right)$ and two of the soma $\left(\left(D_{\text {out }}\right)_{s}\right.$ and $\left.L_{s}\right)$. Also, A-B had the most significant differences (5), while pairs $\mathrm{A}-\mathrm{C}$ and $\mathrm{B}-\mathrm{C}$ had the same differences (3). Finally, Table 2 clearly showed that images of the glia had more differences between groups (three and eight) than images of the body (two and three).

\section{Discussion}

The primary objective of the present study was the analysis of different types of
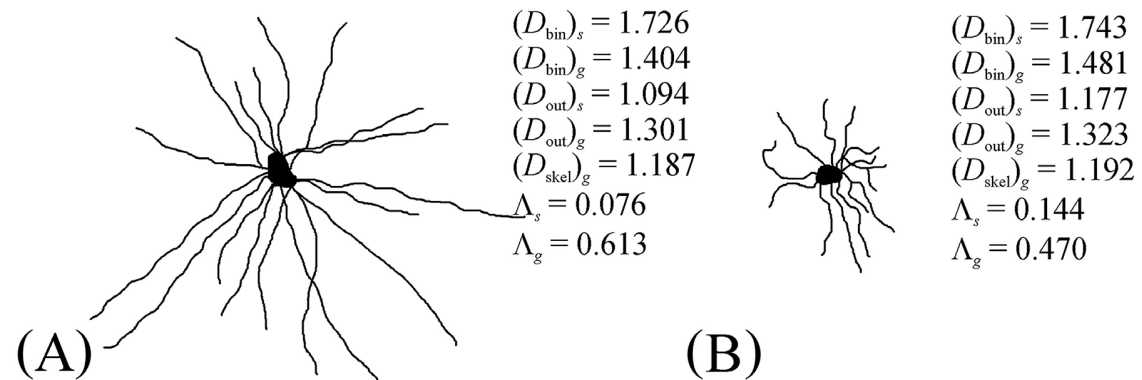

(B)

Figure 3. Examples of binary images of two astrocytes in the examined sample and values of all monofractal parameters for each class. 
Table 2. The results of monofractal parameters between three age groups performing the two-tailed t-test (i.e., $p$ values) for two types of astrocytes. A is the first group of maturation, $\mathrm{B}$ and $\mathrm{C}$ are the first and the second group of aging, respectively. A significant difference is indicated in bold.

\begin{tabular}{ccccc}
\hline Astrocytes & Parameters & A-B & A-C & B-C \\
\hline$\left(D_{\text {bin }}\right)_{s}$ & 0.707 & 0.030 & 0.016 \\
$\left(D_{\text {bin }}\right)_{g}$ & 0.008 & 0.719 & 0.067 \\
Fibrous & $\left(D_{\text {out }}\right)_{s}$ & 0.250 & 0.310 & 0.822 \\
& $\left(D_{\text {out }}\right)_{g}$ & 0.938 & 0.223 & 0.311 \\
& $\left(D_{\text {skel }}\right)_{g}$ & 0.710 & 0.255 & 0.190 \\
& $\Lambda_{s}$ & 0.818 & 0.183 & 0.133 \\
& $\Lambda_{g}$ & $<0.001$ & $<0.001$ & 0.253 \\
\hline & $\left(D_{\text {bin }}\right)_{s}$ & 0.866 & 0.230 & 0.095 \\
& $\left(D_{\text {bin }}\right)_{g}$ & 0.002 & 0.627 & 0.006 \\
& $\left(D_{\text {out }}\right)_{s}$ & 0.002 & 0.011 & 0.443 \\
& $\left(D_{\text {out }}\right)_{g}$ & 0.021 & 0.823 & 0.033 \\
$\left(D_{\text {skel }}\right)_{g}$ & $<0.001$ & $<0.001$ & 0.188 \\
$\Lambda_{s}$ & 0.254 & 0.023 & 0.094 \\
& $\Lambda_{g}$ & $<0.001$ & 0.104 & 0.049 \\
\hline
\end{tabular}

astrocytes from the human PON. The second objective was to study morphological changes during aging. Thus, the present study achieved both goals by calculating the monofractal parameters [24] on the 2D image with the box-counting technique [21]. Also, investigating morphological differences between types and years was performed on the entire sample of astrocytes. However, the quantitative analysis was performed on a binary image, using only monofractal parameters, which determines this study as preliminary.

\subsection{Morphological Analysis of Types}

In recent times, various studies utilized numerous qualitative studies to classify neurons and glial cells in CNS [6]. However, their approaches are mainly based on the inspection of many structural parameters [15] [26]. This study evaluates the morphology of two types of astrocytes, analyzing the binary image's four characteristics (size, shape, complexity and homogeneity), using only monofractal parameters.

The location in the CNS and the size are two significant characteristics among the fibrous and protoplasmic types [4]. The fibrous type can be found throughout white matter, while protoplasmic in the grey matter and first type had a larger size (in the ocular plane) than the second. Also, the qualitative analysis of protoplasmic type postulated short, thick and branched extensions [4]. They extend symmetrically and give them the appearance of star-shaped flakes [5] [6]. The fibrous type also had thin and long sections (generally unbranched) that ex- 
tend radially between nerve fibers and asymmetrical shape in the two dimensions. Earlier qualitative studies also investigated the number of primary extensions, their direction and branching but did not establish apparent differences in types [6]. Other morphological differences, however, have not been quantitatively confirmed. On the other hand, the results of this study clearly showed the difference between types in all four features of the image (Table 1). Furthermore, while there was no significant difference between the bodies, this difference was observed between pictures of the whole cells (Table 1).

As for the size, this study had a surprising result: the protoplasmic type had a larger size than the fibrous (Table 1). However, this result is not supported by the example shown in Figure 3, and anyone can explain this outcome by knowing the true nature of $D_{\text {bin }}$. This parameter is related to the size, but it quantifies the space-filling property of the image. The $D_{\text {out }}$ showed a similar result, and its extreme values are reported previously [24]. Thus, the reader can conclude that protoplasmic astrocytes have a shape closer to an ellipse than fibrous ones. On the other hand, fibrous astrocytes have higher values of complexity and homogeneity (Table 1). However, this is not seen in Figure 3, but, knowing the meaning of $D_{\text {skel }}$ and $\Lambda$, it is easy to conclude that fibrous astrocytes have a greater curvature of the extensions and space than the protoplasmic ones.

\subsection{Morphological Analysis with Age}

The starting point of this part of the investigation was the conclusion that the effect of aging was most clearly evident on astrocyte extensions [8] [29]. Also, the early period of aging quantified the cell complexity and branch extension [4]. Thus, we analyzed the mean values in three age groups and the morphological changes of two types with age. Our results clearly showed a distinct difference in protoplasmic cells compared with fibrous (Table 2).

The most pronounced changes were observed between the second group of maturation and the first group of aging (Table 2). All four features of the image of protoplasmic astrocytes differed significantly, while the difference in cell bodies was observed only in size and shape. The body size, shape, and homogeneity differed substantially between the second group of maturation and the second group of aging. At the same time, the complexity of the whole cell was quite different (Table 2). Finally, the size of the body, the size, shape and homogeneity of the glia differed between the first and second groups of aging (Table 2). In the end, these results support previous qualitative and semi-quantitative findings [30] [31] [32] during the aging process.

\section{Conclusions}

This study quantifies the 2D binary image of astrocytes through only one type of fractal analysis. The fact that the quantitative analysis does not include parameters of textural analysis or the corresponding geometric and computational parameters leads the reader to believe that this is a preliminary study. However, the 
results suggest the opposite.

The monofractal analysis meets both objectives, the first entirely and the second part. However, the fact that parameters ultimately differentiate only the first to the second age group suggests using other parameters that could provide more reliable results, especially in distinguishing the first and third age groups.

Nevertheless, this study shows, for the first time, the detailed quantitative analysis of astrocytes shown on 2D images from the human PON. Further investigation of the morphology of astrocytes should include more parameters than monofractal analysis.

\section{Acknowledgements}

The authors are grateful to Prof. Dušica L. Marić (Department of Anatomy, University of Novi Sad, Serbia) for supervision in histological procedure and image editing, particularly in reconstruction of the trajectory (of the soma and each extension).

\section{Conflicts of Interest}

The authors declare no conflicts of interest regarding the publication of this paper.

\section{References}

[1] Ramón y Cajal, S. (1911) Histologie du système nerveux de l'homme et des vertebras. Maloine, Paris.

[2] del Rio-Hortega, P. (1932) Microglia. In: Penfield, W., Ed., Cytology \& Cellular Pathology of the Nervous System, P.B. Hoeber, New York, 483-534.

[3] Azevedo, F.A.C., Carvalho, L.R.B., Grinberg, L.T., Farfel, J.M., Ferretti, R.E.L., Leite, R.E.P., et al. (2009) Equal Numbers of Neuronal and Nonneuronal Cells Make the Human Brain an Isometrically Scaled-Up Primate Brain. Journal of Comparative Neurology, 513, 532-541. https://doi.org/10.1002/cne.21974

[4] Schmechel, D.E. and Rakic, P. (1979) A Golgi Study of Radial Glial Cells in Developing Monkey Telencephalon: Morphogenesis and Transformation into Astrocytes. Anatomy and Embryology, 156, 115-152. https://doi.org/10.1007/BF00300010

[5] Voigt, T. (1989) Development of Glial Cells in the Cerebral Wall of Ferrets: Direct Tracing of Their Transformation from Radial Glia into Astrocytes. Journal of Comparative Neurology, 289, 74-88. https://doi.org/10.1002/cne.902890106

[6] Radošević, D. (2019) A Morphological Analysis of the Neuronal and Glial Cells in the Human Principal Olivary Nucleus. Thesis, University of Novi Sad, Novi Sad.

[7] Rowitch, D.H. and Kriegstein, A.R. (2010) Developmental Genetics of Vertebrate Glial-Cell Specification. Nature, 468, 214-222. https://doi.org/10.1038/nature09611

[8] Jyothi, H.J., Vidyadhara, D.J., Mahadevan, A., Philip, M., Parmar, S.K., Manohari, S.G., et al. (2015) Aging Causes Morphological Alterations in Astrocytes and Microglia in Human Substantia Nigra Pars Compacta. Neurobiology of Aging, 36, 3321-3333. https://doi.org/10.1016/j.neurobiolaging.2015.08.024

[9] Stefanović, B., Đorđević-Čamba, V., Kojić, Z., Bajčetić, M. and Ćetković, M. (2003) Integrativna Neurobiologija. Mikro knjiga i B\&M, Beograd. (In Serbian)

[10] Levine, M.E., Lu, A.T., Quach, A., Chen, B.H., Assimes, T.L., Bandinelli, S., et al. (2018) 
An Epigenetic Biomarker of Aging for Lifespan and Healthspan. Aging, 10, 573-591. https://doi.org/10.18632/aging.101414

[11] Ely. J.T. and Krone, C.A. (2002) Aging: Predictions of a New Perspective on Old Data. Experimental Biology and Medicine, 227, 939-942. https://doi.org/10.1177\%2F153537020222701101

[12] Campisi J. (2003) Cellular Senescence and Apoptosis: How Cellular Responses Might Inflence Aging Phenotypes. Experimental Gerontology, 38, 5-11. https://doi.org/10.1016/S0531-5565(02)00152-3

[13] Pelvig, D.P., Pakkenberg, H., Stark, A.K. and Pakkenberg, B. (2008) Neocortical Glial Cell Numbers in Human Brains. Neurobiology of Aging, 29, 1754-1762. https://doi.org/10.1016/j.neurobiolaging.2007.04.013

[14] Fabricius, K., Jacobsen, J.S. and Pakkenberg, B. (2013) Effect of Age on Neocortical Brain Cells in 90+ Years Old Human Females-A Cell Counting Study. Neurobiol Aging, 34, 91-99. https://doi.org/10.1016/j.neurobiolaging.2012.06.009

[15] Grosche, A., Grosche, J., Tackenberg, M., Scheller, D., Gerstner, G., Gumprecht, A., et al. (2013) Versatile and Simple Approach to Determine Astrocyte Territories in Mouse Neocortex and Hippocampus. PLoS ONE, 8, e69143. https://doi.org/10.1371/journal.pone.0069143

[16] Lasn, H. (2006) The Principal Inferior Olivary Nucleus in Aging and Alzheimer's Disease. Dissertation, Karolinska Institute, Stocholm.

[17] Lalošević, D., Somer, L.J., Đolai, M., Lalošević, V., Mažibrada, J. and Krnojelac, D. (2005) Mikroskopska laboratorijska tehnika u medicini. Medicinski fakultet Novi Sad-WUS Austrija, Novi Sad. (In Serbian)

[18] Marić, D. (2010) Qualitative and Quantitative Analysis of Adult Human Dentate Nucleus Neurons Morphology. Thesis, University of Novi Sad, Novi Sad.

[19] Krstonošić, B., Milošević, N.T., Marić, D.L. and Babović, S.S. (2015) Quantitative Analysis of Spiny Neurons in the Adult Human Caudate Nucleus: Can It Confirm the Current Qualitative Cell Classification? Acta Neurologica Belgica, 115, 273-280. https://doi.org/10.1007/s13760-014-0365-0

[20] Stojić, D., Radošević, D., Rajković, N., Marić, D.L. and Milošević, N.T. (2020) Classification by Morphology of Multipolar Neurons of the Human Principal Olivary Nucleus. Neuroscience Research, 170, 66-75. https://doi.org/10.1016/j.neures.2020.10.005

[21] Fernandez, E. and Jelinek, H.F. (2001) Use of Fractal Theory in Neuroscience: Methods, Advantages, and Potential Problems. Methods, 24, 309-321.

https://doi.org/10.1006/meth.2001.1201

[22] Ristanović, D., Milošević, N.T., Jelinek, H.F. and Stefanović, I.B. (2009) Mathematical Modelling of Neuronal Dendritic Branching Patterns in Two Dimensions: Application to Retinal Ganglion Cells in the Cat and Rat. Biological Cyberneticsn, 100, Article No. 97. https://doi.org/10.1007/s00422-008-0271-8

[23] Di Ieva, A., Grizzi, F., Jelinek, H.F., Pellionisz, A.J. and Losa, G.A. (2014) Fractals in the Neurosciences, Part I: General Principles and Basic Neurosciences. Neuroscientist, 20, 403-417.

[24] Milošević, N.T. (2016) The Morphology of Brain Neurons: Box Counting Method in Quantitative Analysis of 2D Image. In: Di Ieva, A., Ed., The Fractal Geometry of the Brain, Springer-Verlag, New York, 109-126.

https://doi.org/10.1007/978-1-4939-3995-4 7

[25] Karperien, A. (2007) FracLac for ImageJ. Version 2.0. https://imagej.nih.gov/ij/plugins/fraclac/fraclac-manual.pdf 
[26] Grbatinić, I. and Milošević, N. (2016) Classification of Adult Human Dentate Nucleus Border Neurons: Artificial Neural Networks and Multidimensional Approach. Journal of Theoretical Biology, 404, 273-284. https://doi.org/10.1016/j.jtbi.2016.06.011

[27] Rajković, N., Krstonošić, B. and Milošević, N. (2017) Box-Counting Method of 2D Neuronal Image: Method Modification and Quantitative Analysis Demonstrated on Images from the Monkey and Human Brain. Computational and Mathematical Methods in Medicine, 2017, Article ID: 8967902.

https://doi.org/10.1155/2017/8967902

[28] Riffenburgh, R.H. (1999) Statistics in Medicine. Academic Press, London.

[29] Heneka, M.T., O’Banion, M.K., Terwel, D. and Kummer, M.P. (2010) Neuroinflammatory Processes in Alzheimer's Disease. Journal of Neural Transmission, 117, 919-947. https://doi.org/10.1007/s00702-010-0438-Z

[30] de Brabander, J.M., Kramers, R.J. and Uylings, H.B. (1998) Layer-Specific Dendritic Regression of Pyramidal Cells with Ageing in the Human Prefrontal Cortex. European Journal of Neuroscience, 10, 1261-1269.

https://doi.org/10.1046/j.1460-9568.1998.00137.x

[31] Duan, H., Wearne, S.L., Rocher, A.B., Macedo, A., Morrison, J.H. and Hof, P.R. (2003) Age-Related Dendritic and Spine Changes in Corticocortically Projecting Neurons in Masaque Monkeys. Cerebral Cortex, 13, 950-961. https://doi.org/10.1093/cercor/13.9.950

[32] Kabaso, D., Coskren, P.J., Henry, B.I., Hof, P.R. and Wearne, S.L. (2009) The Electrotonic Structure of Pyramidal Neurons Contributing to Prefrontal Cortical Circuits in Macaque Monkeys Is Significantly Altered in Aging. Cerebral Cortex, 19, 2248-2268. https://doi.org/10.1093/cercor/bhn242 